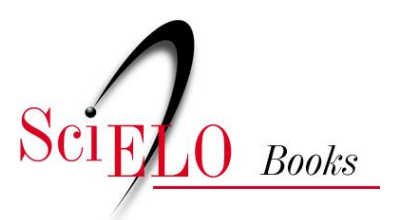

กำ

FIOCRUZ

Ipea $\begin{array}{ccc}\text { Instituto de Pesquisa } & \text { Ministério da } \\ \text { Saúde } & \text { Secretaria de } \\ \text { Assuntos Estratégicos }\end{array}$

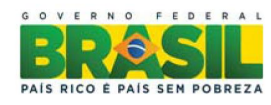

\title{
Princípios do sistema de saúde brasileiro
}

\author{
José Carvalho de Noronha \\ Telma Ruth Pereira
}

\section{SciELO Books / SciELO Livros / SciELO Libros}

NORONHA, JC., and PEREIRA, TR. Princípios do sistema de saúde brasileiro. In FUNDAÇÃO OSWALDO CRUZ. A saúde no Brasil em 2030 - prospecção estratégica do sistema de saúde brasileiro: organização e gestão do sistema de saúde [online]. Rio de Janeiro: Fiocruz/Ipea/Ministério da Saúde/Secretaria de Assuntos Estratégicos da Presidência da República, 2013. Vol. 3. pp. 19-32. ISBN 978-85-8110-017-3. Available from SciELO Books <http://books.scielo.org>.

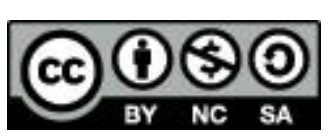

All the contents of this chapter, except where otherwise noted, is licensed under a Creative Commons Attribution-Non Commercial-ShareAlike 3.0 Unported.

Todo o conteúdo deste capítulo, exceto quando houver ressalva, é publicado sob a licença Creative Commons Atribuição Uso Não Comercial - Partilha nos Mesmos Termos 3.0 Não adaptada.

Todo el contenido de este capítulo, excepto donde se indique lo contrario, está bajo licencia de la licencia Creative Commons Reconocimento-NoComercial-CompartirIgual 3.0 Unported. 
Princípios do Sistema de Saúde Brasileiro 


\section{PRINCÍPIOS DO SISTEMA DE SAÚDE BRASILEIRO \\ José Carvalho de Noronha \\ Telma Ruth Pereira}

Egresso das sombras que cobriram o país em 1964 e amparado, como disse Ulysses Guimarães (GUIMARÃES, 1988), no discurso por ocasião da promulgação da Constituição Federal, pelo "representativo e oxigenado sopro de gente, de rua, de praça, de favela, de fábrica, de trabalhadores, de cozinheiros, de menores carentes, de índios, de posseiros, de empresários, de estudantes, de aposentados" o Brasil trafegou em direção à democracia política na década de 1980.

A abertura da sociedade para o debate ampliado de suas opções de desenvolvimento e os avanços institucionais promovidos pela Constituição Federal de 1988, sobretudo na área social, como foi o caso da Seguridade Social, introduziram, no dizer de Ulysses Guimarães "o homem no Estado, fazendo-o credor de direitos e serviços, cobráveis inclusive com o mandado de injunção. (...) A Constituição é caracteristicamente o estatuto do homem" (GUIMARÃES, 1988).

Assim, a Constituição Federal de 1988, marco da redemocratização do país, estabeleceu garantias fundamentais a todo cidadão, institucionalizando seus direitos. E é nela que se encontra a base do sistema de saúde brasileiro, no Título VIII da Ordem Social que integra conceitualmente, sob a denominação de Seguridade Social, o conjunto de ações de iniciativa dos poderes públicos e da sociedade destinados a assegurar os direitos relativos à saúde, à previdência e à assistência social, como expresso no art. 194 (BRASIL, 1988). Como Ulysses lembrou em seu discurso, naquela ocasião, "o Brasil é o quinto país a implantar o instituto moderno da seguridade, com a integração de ações relativas à saúde, à previdência e à assistência social, assim como a universalidade dos benefícios para os que contribuam ou não (...)" (GUIMARÃES, 1988).

Os pilares desse instituto já se anunciam no Art. $3^{\circ}$, que define os objetivos fundamentais da República: I - construir uma sociedade livre, justa e solidária; II — garantir o desenvolvimento nacional; III - erradicar a pobreza e a marginalização e reduzir as desigualdades sociais e regionais; IV — promover o bem de todos, sem preconceitos de origem, raça, sexo, cor, idade e quaisquer outras formas de discriminação. E, ainda, no Título II (Dos Direitos e Garantias Fundamentais), artigo 
$5^{\circ}$ — "Todos são iguais perante a lei, sem distinção de qualquer natureza, garantindo-se aos brasileiros e aos estrangeiros residentes no País a inviolabilidade do direito à vida, à liberdade, à igualdade, à segurança e à propriedade, (...)" (BRASIL, 1988). Os direitos sociais são descritos e assegurados no artigo $6^{\circ}$ — "São direitos sociais a educação, a saúde, o trabalho, o lazer, a segurança, a previdência social, a proteção à maternidade e à infância, a assistência aos desamparados, na forma desta Constituição" (BRASIL, 1988). em nosso país.

Direito e Justiça são, assim, os conceitos que presidem o campo da saúde

Signatário da Declaração Universal dos Direitos Humanos, proclamada pela Assembleia Geral da ONU pela Resolução 217-A, de 10 de dezembro de 1948, o Brasil se posicionou além do texto que consagra a saúde como direito fundamental da humanidade. Naquela Declaração, que tem apenas valor moral e não o caráter vinculante do sistema legal internacional segundo Dallari (DALLARI, [200-?]) o direito à saúde é reconhecido como resultado do direito a um nível de vida que resulte em bem-estar.

Artigo 25 - 1. "Toda a pessoa tem direito a um nível de vida suficiente para lhe assegurar e à sua família a saúde e o bem-estar, principalmente quanto à alimentação, ao vestuário, ao alojamento, à assistência médica $e$ ainda quanto aos serviços sociais necessários, e tem direito à segurança no desemprego, na doença, na invalidez, na viuvez, na velhice ou noutros casos de perda de meios de subsistência por circunstâncias independentes da sua vontade". (ONU, 1948)

É no Pacto Internacional de Direitos Econômicos, Sociais e Culturais, aprovado pela Assembleia Geral, através da resolução 2200 A (XXI), de 16 de Dezembro de 1966, que o direito à saúde torna-se mais explícito:

Art. 12 - 1. Os Estados Partes no presente Pacto reconhecem o direito de toda pessoa ao desfrute do mais alto nível possível de saúde física e mental.

2. As medidas que os Estados Partes no presente Pacto tomarem com vista a assegurar o pleno exercício deste direito deverão compreender as medidas necessárias para assegurar:

a) A diminuição da mortinatalidade e da mortalidade infantil, bem como o são desenvolvimento da criança;

b) O melhoramento de todos os aspectos de higiene do meio ambiente e da higiene industrial; 
c) A profilaxia, tratamento e controle das doenças epidêmicas, endêmicas, profissionais e outras;

d) A criação de condições próprias a assegurar a todas as pessoas serviços médicos e ajuda médica em caso de doença" (ONU, 1966).

Embora a saúde esteja associada ao nível de vida, a concepção traz embutida a visão formulada pela Organização Mundial de Saúde em 1946: "A saúde é um estado de completo bem-estar físico, mental e social, e não apenas a ausência de doenças" (WHO, 1946). A Constituição Brasileira, em seu art. 196, a reafirma de modo mais abrangente: "A saúde é direito de todos e dever do Estado, garantido mediante políticas sociais e econômicas que visem à redução do risco de doença e de outros agravos e ao acesso universal e igualitário às ações e serviços para sua promoção, proteção e recuperação.” (BRASIL, 1988). É um artigo programático, não impositivo, sempre permanente. Trata-se de um princípio de justiça normativa que quer ser aplicada e torna-se referencial como uma política de direitos.

O conceito de justiça subjacente ao conceito de saúde como proteção social também está presente no artigo $3^{\circ}$ do texto constitucional, ao garantir uma sociedade livre, justa e solidária, com redução das desigualdades sociais e regionais e no artigo $5^{\circ}$ que assinala a igualdade de todos perante a lei. Afirma-se, assim, o princípio da equidade.

O enunciado deste princípio considera haver diferenças sociais entre os cidadãos, fruto de desigualdades construídas histórica e politicamente que devem ser vencidas. Tem sido consenso na literatura os modos como essas desigualdades se refletem na área da saúde: na cobertura, no acesso, na distribuição dos recursos de saúde (físicos e financeiros) e no uso dos serviços (VIANNA, 2001, TRAVASSOS ET al., 2006, CASTRO, 2006).

O artigo 196 considera três aspectos: a relação direito e dever; a saúde como resultante de políticas sociais e econômicas; e o acesso universal e igualitário.

O direito à saúde e à justiça social configura-se como um dos direitos sociais garantidos na Constituição Federal, um direito público subjetivo e um impostergável dever do Estado.

O direito público subjetivo à saúde representa prerrogativa jurídica da República (art. 196). Traduz bem jurídico constitucionalmente tutelado, por cuja integridade deve velar, de maneira responsável, o Poder Público, a quem incumbe formular - e implementar - políticas sociais e econômicas que visem garantir, aos cidadãos, o acesso universal e igualitário à assistência médicohospitalar. O caráter programático da regra inscrita no art. 196 da Carta 
Política - que tem por destinatários todos os entes políticos que compõem, no plano institucional, a organização federativa do Estado Brasileiro - não pode converter-se em promessa institucional inconsequente, sob pena de o Poder Público, fraudando justas expectativas nele depositadas pela coletividade, substituir, de maneira ilegítima, o cumprimento de seu impostergável dever por um gesto de infidelidade governamental ao que determina a própria Lei Fundamental do Estado (MELLO, 2000, apud TENÓRIO, 2008).

O segundo aspecto encontra-se no fundamento das políticas públicas em saúde voltadas para o reconhecimento da determinação social da saúde, o que implica em considerar os aspectos sociais, econômicos, políticos, culturais e ambientais que atuam sobre a saúde. Esse conceito foi, de certa forma, adotado pela OMS em seu relatório "Diminuindo diferenças: a prática das políticas sobre determinantes sociais da saúde” (WHO, 2011). Nesse modelo, são considerados os determinantes estruturais que compreendem a distribuição de renda, o preconceito baseado em valores relativos a gênero e etnia, e os determinantes intermediários expressos nas condições de vida, nos aspectos psicossociais, nos elementos comportamentais e/ou biológicos e no próprio sistema de saúde.

A universalidade da saúde evidenciada no artigo 194 é reforçada no art. 196, quando explicita a garantia do "acesso universal e igualitário às ações e serviços para sua promoção, proteção e recuperação” (BRASIL, 1988).

Com a universalidade, o sistema de saúde brasileiro prescreve o rompimento do padrão anterior de políticas públicas segmentadas, para que se torne público, universal, e igualitário, e se realize como uma política inclusiva.

Originada de uma concepção de Estado de bem-estar social, a Seguridade Social tem fixados como seus objetivos, no art. 194, § único:

(i) universalidade da cobertura e do atendimento; (ii) uniformidade $e$ equivalência dos benefícios e serviços às populações urbanas e rurais; (iii) seletividade e distributividade na prestação dos benefícios e serviços; (iv) irredutibilidade do valor dos benefícios; (v) equidade na forma de participação no custeio; (vii) diversidade da base de financiamento; e (vii) caráter democrático e descentralizado da administração, mediante gestão quadripartite, com participação dos trabalhadores, dos empregadores, dos aposentados e do governo nos órgãos colegiados (BRASIL, 1988).

Outras disposições sobre a seguridade social dizem respeito à definição de contribuições específicas para seu financiamento. Em primeiro lugar, que ela: 
será financiada por toda a sociedade, de forma direta e indireta, nos termos da lei, mediante recursos provenientes dos orçamentos da União, dos Estados, do Distrito Federal e dos Municípios, e das seguintes contribuições sociais:

I - do empregador, da empresa e da entidade a ela equiparada na forma da lei, incidentes sobre:

a) a folha de salários e demais rendimentos do trabalho pagos ou creditados, a qualquer título, à pessoa física que lhe preste serviço, mesmo sem vínculo empregatício;

b) a receita ou o faturamento;

c) o lucro;

II - do trabalhador e dos demais segurados da previdência social, não incidindo contribuição sobre aposentadoria e pensão concedidas pelo regime geral de previdência social;

III - sobre a receita de concursos de prognósticos.

IV - do importador de bens ou serviços do exterior, ou de quem a lei a ele equiparar. (BRASIL, 1988, art. 195)

Para Werneck Vianna, a Constituição “estabelece um sistema universal de seguridade social, universal e integrado, o que tem implicações simbólicas e práticas. (...) as implicações simbólicas podem ser resumidas na vinculação da proteção social ao conceito de cidadania positivada; as implicações práticas decorrem do princípio do financiamento compartilhado de benefícios contributivos e não contributivos." (WERNECK VIANNA, 2009).

artigo 198:

As diretrizes para a organização do sistema de saúde são fixadas no

as ações e serviços públicos de saúde integram uma rede regionalizada e hierarquizada e constituem um sistema único, organizado de acordo com as seguintes diretrizes:

I - descentralização, com direção única em cada esfera de governo;

II - atendimento integral, com prioridade para as atividades preventivas, sem prejuízo dos serviços assistenciais [e];

III — participação da comunidade. (BRASIL, 1988).

A descentralização na saúde tem sido objeto de inúmeras análises (TOBAR, 1991, WAGNER, 2006, BERENGER, 1996), e traz consigo os conceitos de redistribuição 
do poder e separação entre as competências das administrações federal, estaduais e municipais. A ideia inicial de um pacto federativo entre os diferentes níveis de governo com papéis claramente identificados na gestão do SUS tem sido objeto de críticas em função do esvaziamento da atuação dos governos estaduais e o privilégio dado à municipalização (CORDEIRO, 2001). No entanto, houve, sem dúvida, grandes avanços quanto à transferência de responsabilidades e recursos do nível federal para estados e municípios e com o estabelecimento de fóruns de negociação entre poderes, as comissões intergestores tripartites e bipartites (LEVCOVITZ ET AL., 2001, VIANA e LIMA, 2011).

A ideia plasmada de que as ações e serviços públicos de saúde constituem um sistema único e integrado em uma rede regionalizada e hierarquizada, traz consigo uma noção que transcende a verticalidade formal jurídico-administrativa de cada poder responsável pelo cuidado à saúde. As disputas políticas devem enfrentar o conceito de solidariedade e pactuação, respeitando a autonomia de cada poder da federação. Como bem observou Milton Santos:

O território, hoje, pode ser formado de lugares contíguos e de lugares em rede: São, todavia, os mesmos lugares que formam redes e que formam o espaço banal. São os mesmos lugares, os mesmos pontos, mas contendo simultaneamente funcionalidades diferentes, quiçá divergentes ou opostas. Esse acontecer simultâneo, tornado possível graças aos milagres da ciência, cria novas solidariedades: a possibilidade de um acontecer solidário, malgrado todas as formas de diferença, entre pessoas, entre lugares. (SANTOS, 2005)

Esse "acontecer solidário" se constitui em um dos grandes impasses na questão da regionalização, uma vez que mobiliza poderes, interesses e divergências políticas entre os níveis de governo.

E, embora prevista no texto constitucional, é apenas a partir de 2001 que a regionalização da saúde começa a tomar corpo com a instituição da primeira Norma Operacional de Assistência à Saúde (NOAS) (BRASIL, 2002), caracterizando-se, posteriormente, em 2006, como diretriz organizativa do Pacto pela Saúde. No Programa Mais Saúde: Direito de Todos: 2008-2011 (BRASIL, 2007), o Ministério da Saúde institui os Territórios Integrados de Atenção à Saúde - TEIAS, como modelo de organização de redes de atenção à saúde, consoante os princípios de universalidade, integralidade e equidade. Mais recentemente, o Decreto 7.508/2011, que regulamenta a Lei Orgânica da Saúde (Lei 8.080/90), adota o conceito de região de saúde como o "espaço geográfico contínuo constituído por agrupamentos de Municípios limítrofes, delimitado a partir de identidades culturais, econômicas e sociais e de redes de comunicação e infraestrutura de transportes compartilhados, com a finalidade de integrar a organização, o planejamento e a execução de ações e serviços de saúde" (BRASIL, 2001). 
Esses sucessivos esforços para a regulamentação de redes regionalizadas estabelecem um conjunto de instrumentos de planejamento, coordenação e regulação como: Plano Diretor de Regionalização (PDR), Plano Diretor de Investimentos (PDI), câmaras técnicas, comissões regionais, entre outros.

Porém, muito além de técnicas e instrumentos, "a regionalização deve ser encarada como um processo de pactuação política no âmbito de planejamento territorial e nacional entre entes federados - não necessariamente contíguos territorialmente, porém solidários organizacionalmente pelos usos do território (fixos e fluxos dinamizados por racionalidades diversas)" (VIANA, 2008). E é este o objetivo do Contrato Organizativo de Ação Pública da Saúde, previsto no Decreto 7.508/2011, um acordo de colaboração firmado entre os entes federativos visando organizar e integrar as ações e serviços de saúde em uma rede regionalizada e hierarquizada, assinalando responsabilidades, recursos, formas de avaliação de desempenho. Um sistema de saúde cooperativo, construído com base em relações colaborativas entre os entes federados e com ações coordenadas em prol da otimização dos recursos disponíveis e tendo como objetivo final garantir o acesso e a integralidade da atenção e promover a equidade.

A Lei n. ${ }^{\circ}$ 8.080/1990, a chamada Lei Orgânica da Saúde, retoma preceitos constitucionais da reforma sanitária democrática dos anos 80, apesar de circunscrever os dispositivos relativos às ações e serviços de saúde apenas àqueles financiados pelo poder público (SUS) (BRASIL, 1990). O Decreto No 7.508, de 28 de junho de 2011, que a regulamenta, enfatiza os aspectos críticos de funcionamento do SUS, como a organização do SUS, a relação entre os gestores e a questão dos medicamentos.

Desde a promulgação da Constituição Federal, muitos foram os avanços do Sistema Único de Saúde, expressos na melhoria das condições de saúde da população e na cobertura dos serviços de saúde. Entretanto alguns impasses deverão ser enfrentados, sobretudo nos aspectos relativos ao financiamento setorial e às relações entre o público e o privado.

Um dos aspectos fundamentais estabelecidos na Constituição de 1988 foi a definição clara de uma base específica de contribuições para financiamento da Seguridade Social mencionada anteriormente. Contudo a década de 1990 assistirá ao início das tentativas de impor ao país uma "contrarreforma sanitária", aprofundando uma subtração de recursos da saúde que reduzirá significativamente a política de incremento de gastos em meados dos anos 80, quando se reduzem as transferências da Previdência para a Saúde.

A criação, em 1994, do Fundo Social de Emergência (FSE) (EC n¹0) retirará parte substantiva dos recursos disponíveis para os gastos sociais da União, consolidando a drástica redução dos ganhos proporcionados pela Constituição de 1988. 
Em 1996, após a interrupção das transferências de recursos para a Saúde por parte da Previdência Social, a questão do financiamento retorna como questão essencial para uma política igualitária e universalista de saúde. Recursos para investimento para recuperação de uma rede sucateada pelo subfinanciamento são buscados através de fontes externas. É aprovada uma nova fonte de receita para a Seguridade Social, a Contribuição Provisória sobre Movimentação Financeira CPMF, logo onerada, como as demais fontes, pelo Fundo de Estabilização Fiscal (nova denominação do FSE), que depois se transformará na Desvinculação de Receitas da União, a DRU (BRASIL, 2007).

O Ato das Disposições Constitucionais Transitórias (Art. 55) havia fixado em trinta por cento, no mínimo, a proporção do orçamento da Seguridade Social a ser destinada ao setor saúde (BRASIL, 1988). Pretendeu-se, além de fixar em definitivo aquele percentual da receita das contribuições sociais, vincular parte da receita de estados e municípios à saúde, à semelhança da educação, através da Proposta de Emenda Constitucional 169/93. Apenas em 2000 é retomada uma modificação da proposta, finalmente aprovada, a Emenda Constitucional n. ${ }^{\circ}$ 29/2000 (BRASIL, 2000), que manteve a vinculação das receitas de estados e municípios em 12 e 15 por cento respectivamente, mas rompeu a dedicação dos trinta por cento das contribuições sociais à Saúde, fixando apenas o seu crescimento a variações do Produto Interno Bruto - PIB. Se essa emenda, por um lado, permitiu uma estabilidade de receita, por outro quebrou de vez a ideia de financiamento solidário da seguridade e dificultou acréscimos superiores à variação do PIB. Essa não é uma questão menor, pois, desde 1994, com a criação do FSE, já haviam sido subtraídos da Seguridade 20\% de sua arrecadação, que se mantiveram permanentes sob a forma de DRU, recursos em quase sua totalidade destinados ao pagamento dos encargos financeiros da União. Em 2007, a situação é agravada com a extinção da CPMF. Em 2011 é aprovada a Lei 141 que regulamenta a EC 29, registrando o que deve ser considerado como despesas em ações e serviços de saúde, sem estabelecer fontes adicionais de contribuição (BRASIL, 2012).

Um ponto talvez mais relevante para a elaboração de propostas de correção de rumo do financiamento das ações e serviços de saúde no país situa-se na esfera da justiça tributária. A carga tributária no Brasil incide exageradamente sobre a folha de salários e sobre o consumo e poupa a tributação da renda, e, por conta da predominância dos tributos indiretos, atinge com mais intensidade os decis de renda familiar mais baixa (IPEA, 2012). A progressividade que poderia ser obtida por meio dos impostos sobre a renda é bastante limitada no Brasil, em função do pequeno número de alíquotas (4) e do percentual de incidência da alíquota máxima (27,5\%).

Ainda há gastos que dizem respeito à justiça tributária e não são contabilizados no gasto total com saúde. São conhecidos como subsídios ou renúncia fiscal, isenções e abatimentos. Um dos tipos de subsídio são as desonerações fiscais, os 
gastos públicos indiretos, assim denominados por serem contabilizados como gastos públicos sem terem sido realizados pelo Estado, mas por ente privado, como os gastos que permitem dedução do valor do tributo a pagar por empresas e famílias, ou mesmo descontos tributários, sob o argumento de beneficiar determinados setores. O fato é que esse tipo de gasto diminui o montante arrecadado pelo Estado, ou seja, reduz a carga tributária e, portanto, o que seria a receita pública caso não existisse. Assim, deveria ser profundamente analisado para se avaliar se o benefício gerado corresponde ao recurso que se perde.

Outra análise do financiamento do setor Saúde diz respeito ao peso do gasto com saúde realizado pelas famílias sobre suas rendas. Esse tipo de gasto, conhecido como gasto privado direto ou desembolso com saúde, é comumente voltado para a compra de medicamentos, consultas, exames, internações e tratamento. Os dados da Pesquisa de Orçamentos Familiares (POF/IBGE) mostram que o gasto privado direto com saúde representou quase $7,2 \%$ do orçamento familiar, sendo o quarto item entre os maiores gastos, após habitação, alimentação e transporte (IBGE, 2010).

A estrutura do sistema de saúde brasileiro apresenta muitas e antigas sobreposições público-privadas. A segmentação do sistema se dá de forma institucionalizada, e muitas vezes a interferência do setor privado sobre o interesse público se dá na contramão da universalidade e da equidade no atendimento, com decisões governamentais que promovem incentivos diretos e indiretos para o desenvolvimento do mercado privado de saúde, tanto na prestação de serviços quanto na gestão privada da assistência, paralela à ampliação da cobertura pública.

São necessários atores estratégicos para o sucesso na implantação de uma política de saúde que faça cumprir a universalidade e equidade inscritas no texto constitucional. Mas, já há algum tempo, os atores estratégicos nesse processo não têm sido nem a classe trabalhadora organizada (que demanda planos privados e os trata como objeto de negociação trabalhista entre sindicatos e as grandes empresas industriais), nem os profissionais da saúde (que buscam aumentar a produção destinada ao demandante que paga o maior preço, portanto não o SUS, mas os planos privados). Os próprios servidores públicos, tanto civis como militares, e seus dependentes têm assistência exclusiva para eles e em parte financiada com recursos públicos, o que constitui um empecilho a qualquer melhora do SUS, pois enquanto estiverem protegidos de outra forma, toda sua atuação em prol desse sistema se daria por ideologia, compaixão ou amor ao trabalho, mas não por ser o sistema que queiram usar para si ou para os seus. Esses atores fazem parte da nossa sociedade, e sua ambiguidade em relação à universalidade na proteção social nada mais é que o espelho da segmentação da sociedade brasileira.

A política de saúde deveria ser reorientada para interferir em prol de uma proteção social que defenda os interesses públicos, baseada em princípios 
solidários. Para isso é preciso uma política que proteja os objetivos do SUS, mesmo que mantendo híbrido o sistema de saúde brasileiro, mas tornando-o mais voltado para as necessidades de uma proteção social solidária e menos desigual. Certamente o ponto central está em simultaneamente avançar na redução da injustiça fiscal e propiciar o aumento de recursos públicos para o financiamento das ações e serviços de saúde e regular de forma mais efetiva as relações entre o SUS e o segmento de serviços privados, em particular o de seguros e planos de saúde.

Na promoção de maior justiça fiscal, há propostas direcionadas a um aumento do número de alíquotas do Imposto de Renda de Pessoa Física (IRPF), com a criação de alíquotas de tributação mais elevadas coerentes com o padrão internacional, bem como a limitação das isenções à saúde para cobertura de danos catastróficos. Talvez a imposição de um teto, à semelhança da dedução dos gastos com educação, fosse uma solução de transição aceitável.

Também é relevante discutir a questão do "rendimento do trabalho com outras vestes", que constitui uma fonte importante de elisão fiscal por parte das empresas (SOARES et al., 2009). Os planos de saúde coletivos correspondem a esses casos e constituem-se em uma fonte importante de salário indireto. Pode ser necessário, como ocorre em muitos países, imputar essas rendas à renda tributável ou criar um imposto específico para tributar esse tipo de renda.

Outras sugestões de caráter mais geral também são abordadas, como a progressividade na taxação do lucro presumido (maior aproximação entre o IRPF e o Imposto de Renda de Pessoa Jurídica) e na tributação progressiva da renda do capital (SOARES et al., 2009).

Um grande desafio consiste em repor os compromissos da União no financiamento setorial. Há um debate recorrente, seja sobre a criação de tributo adicional com destinação específica, seja sobre a vinculação, à semelhança dos estados e municípios, de uma parcela da receita da União para as ações e serviços de saúde. Foi recomendação do Conselho de Desenvolvimento Econômico e Social o cumprimento do mandamento constitucional da integridade da Seguridade Social, com a garantia da vinculação e diversidade de fontes. Este poderia ser o caminho mais curto e melhor, com aumento progressivo de sua destinação para a saúde, mediante a redução dos gravames sobre as contribuições da seguridade da desvinculação das receitas da União, de forma a atingir os 30\% originais (BRASIL, 2011).

Poder-se-ia ainda cogitar da criação de um imposto sobre os prêmios de planos de saúde acima de determinado valor. Estimando-se que cerca de quatro milhões de pessoas estariam pagando prêmios anuais da ordem de $\mathrm{R} \$$ 6.000,00 por ano, teríamos recursos da ordem de 24 bilhões de reais para serem tributados. Uma alíquota de 5\% injetaria 1,2 bilhões nos sistema público. 
Na busca de um aumento da eficiência dos gastos, outra dimensão importante a ser enfrentada é a necessária integração das redes assistenciais e dos próprios modelos assistenciais. Torna-se imprescindível que não haja diferenciação na qualidade do atendimento às necessidades de cuidados da população coberta por planos de saúde e daquela não coberta e que o acesso, presteza e uso sejam definidos pelas necessidades dos usuários, e não pela sua capacidade de pagamento. Também, que a lógica organizacional dos prestadores seja integrada, de forma a evitar duplicação e desperdício.

Por toda a parte há um debate crescente em torno do estabelecimento de redes assistenciais integradas, tanto horizontais (em um espaço territorial definido) como verticais (entre os diversos níveis de complexidade dos serviços prestados). A utilização universal de identificadores únicos para serviços de saúde, como deveria ser a implantação do cartão nacional de saúde, facilitaria essa integração e contribuiria para simultaneamente aumentar a eficiência dos gastos e a qualidade dos cuidados prestados. Simplificaria para os prestadores os mecanismos burocráticos de compensação financeira pelos serviços prestados e lhes facilitaria a não discriminação por capacidade de pagamento. O Ministério da Saúde e a Agencia Nacional de Saúde Suplementar deverão estar atentos para desempenhar mais intensamente papéis integradores que deem conta desses desafios.

É urgente garantir princípio da universalidade da cobertura e do atendimento da Seguridade Social em todos seus componentes. Isso passa pela recomposição do seu orçamento integrado e aumento da parcela da Saúde, de acordo com os preceitos constitucionais vigentes à época da Constituição de 88.

Lembrando Bobbio:

o problema que temos diante de nós não é filosófico, mas jurídico e, num sentido mais amplo, político. Não se trata de saber quais e quantos são esses direitos, qual é a sua natureza e seu fundamento, se são direitos naturais ou históricos, absolutos ou relativos, mas sim qual é o modo mais seguro para garanti-los, para impedir que, apesar das solenes declarações, eles sejam continuamente violados. (BOBBIO, 1992). 


\section{1 | REFERÊNCIAS BIBLIOGRÁFICAS}

BERENGER, M. M. Descentralização ou Desconcentração: AIS -SUDS -SUS. 1996. 79f. Dissertação (Mestrado em Administração Pública) - Escola Brasileira de Administração Pública, Fundação Getúlio Vargas, Rio de Janeiro. 1996. Disponível em http://bibliotecadigital.fgv.br/dspace/ bitstream/handle/10438/8090/000065512.pdf? sequence=1. Acesso em: 25 mar 2013.

BOBBIO, N. A era dos direitos. Rio de Janeiro, Campus, 1992. Pag. 25

BRASIL. MINISTÉRIO DA SAÚDE. Mais Saúde: direito de todos - 2008-2011. 5. ed. Brasília, 2007. 128 p. Disponível em: <http://bvsms.saude.gov.br/bvs/pacsaude/programa.php>. Acesso em: 20 abr. 2013.

BRASIL. MINISTÉRIO DA SAÚDE. GABINETE DO MINISTRO. Norma Operacional da Assistência à Saúde: Portaria GM / MS 373* (27 de fevereiro de 2002). Brasília: Ministério da Saúde, 2002.

BRASIL. PRESIDÊNCIA DA REPÚBLICA. Constituição da República Federativa do Brasil: promulgada em 5 de outubro de 1988. Brasília: Senado Federal, 1988. Disponível em http://www. planalto.gov.br/ccivil_03/constituicao/constituicao.htm. Acesso em 10/01/2013.

BRASIL. PRESIDÊNCIA DA REPÚBLICA. Lei n. 8.080, de 19 de setembro de 1990: dispõe sobre as condições para a promoção, proteção e recuperação da saúde, a organização e o funcionamento dos serviços correspondentes e dá outras providências. Brasília, 1990.

BRASIL. PRESIDÊNCIA DA REPÚBLICA. Decreto n. 7.508, de 28 de junho de 2011: regulamenta a Lei n. 8.080, de 19 de setembro de 1990, para dispor sobre a organização do Sistema Único de Saúde - SUS, o planejamento da saúde, a assistência à saúde e a articulação interfederativa, e dá outras providências. Brasília, 2011.

BRASIL. PRESIDÊNCIA DA REPÚBLICA. Emenda Constitucional No 29, de 13 de setembro de 2000: Altera os arts. 34, 35, 156, 160, 167 e 198 da Constituição Federal e acrescenta artigo ao Ato das Disposições Constitucionais Transitórias, para assegurar os recursos mínimos para o financiamento das ações e serviços públicos de saúde. Brasília, 2000.

BRASIL. PRESIDÊNCIA DA REPÚBLICA. Lei Complementar $\mathrm{N}^{\circ}$ 141, de 13 de janeiro de 2012: regulamenta o $\S 3^{\circ}$ do art. 198 da Constituição Federal para dispor sobre os valores mínimos a serem aplicados anualmente pela União, Estados, Distrito Federal e Municípios em ações e serviços públicos de saúde; estabelece os critérios de rateio dos recursos de transferências para a saúde e as normas de fiscalização, avaliação e controle das despesas com saúde nas 3 (três) esferas de governo; revoga dispositivos das Leis nos 8.080, de 19 de setembro de 1990, e 8.689, de 27 de julho de 1993; e dá outras providências. Brasília, 2012.

BRASIL. PRESIDÊNCIA DA REPÚBLICA. CONSELHO DE DESENVOLVIMENTO ECONÔMICO E SOCIAL. Indicadores de iniquidade do Sistema Tributário Nacional: relatório de observação $n^{\circ}$ 2. 2. ed. Brasília, DF: CDES, 2011.

CASTRO, M.S.M. Desigualdades sociais no uso de internações hospitalares no Brasil: o que mudou entre 1998 e 2003. Ciência \& Saúde Coletiva, v. 11, n. 4, p. 987-998, 2006.

CORDEIRO, H. Descentralização, universalidade e equidade nas reformas da saúde. Ciênc. saúde coletiva, São Paulo, v. 6, n. 2, 2001. Disponível em http://www.scielosp.org/pdf/csc/v6n2/7005. pdf. Acesso em: 20 mar 2013. 
DALLARI, S. G. DIREITO SANITÁRIO. [200-?] Disponível em http://gesan.ndsr.org/ docmanualespecializacao03DireitoSanitario.pdf. Acesso em: 16 fev 2013.

GUIMARÃES, U. Discurso proferido na sessão de 5 de outubro de 1988 publicado no DANC de 5 de outubro de 1988, p. 14380-14382. Disponível em: http://apache.camara.gov.br/portal/ arquivos/Camara/internet/plenario/discursos/escrevendohistoria/constituinte-1987-1988/pdf/ Ulysses\%20Guimaraes\%20-\%20DISCURSO\%20\%20REVISADO.pdf. Acesso em 15/02/2013.

INSTITUTO BRASILEIRO DE GEOGRAFIA E ESTATÍSTICA (IBGE). Pesquisa de Orçamentos Familiares 2008-2009. Despesas, Rendimentos e Condições de Vida, IBGE, 2010. Disponível em http://www.ibge.gov.br/home/estatistica/populacao/condicaodevida/pof/2008_2009/ POFpublicacao.pdf. Acesso em: 2 abr.2013.

IPEA. Equidade Fiscal no Brasil: Impactos Distributivos da Tributação e do Gasto Social. Comunicados do Ipea, 92, 2011. Disponível em http://www.ipea.gov.br/portal/images/stories/ PDFs/comunicado/110519_comunicadoipea92.pdf. Acesso em : 5 abr 2013.

LEVCOVITZ, E.; LIMA, L. D.; MACHADO, C. V. Política de saúde nos anos 90: Relações intergovernamentais e o papel das Normas Operacionais Básicas. Ciênc. saúde coletiva; 6(2):269-318, 2001. Disponível em http://www.scielosp.org/pdf/csc/v6n2/7003.pdf. Acesso em: 21 mar 2013.

ONU. Declaração Universal dos Direitos do Homem. Disponível em http://www.ohchr.org/EN/ UDHR/Documents/UDHR_Translations/por.pdf. Acesso em 16/02/2013.

ONU. Pacto Internacional sobre os Direitos Econômicos, Sociais e Culturais (PIDESC). Disponível em http://www.gddc.pt/direitos-humanos/Ficha_Informativa_2.pdf. Acesso em: 16 fev 2013.

SANTOS, M. O retorno do território. In: Territorio y movimientos sociales. OSAL, Observatorio Social de América Latina, año VI, no. 16. CLACSO, Consejo Latinoamericano de Ciencias Sociales, Buenos Aires, Argentina: Argentina. 2005. Disponível em http://biblioteca.clacso.edu.ar//ar/ libros/osal/osal16/D16Santos.pdf. Acesso em: 25 fev 2013.

SOARES, S. ET AL. O potencial distributivo do imposto de renda de pessoa física(IRPF). Brasília: IPEA, 2009. Texto de Discussão n. ${ }^{\circ} 1433$.

TENÓRIO, A.A. O Direito à Saúde. Dever do Estado. 2008. Disponível em http://www.oabsp.org. br/subs/auriflama/institucional/jornal-oab-local/direito-a-saude-dever-do-estado. Acesso em: 15 mar 2013.

TOBAR, F. O Conceito de Descentralização: Usos e Abusos. Planejamento e Políticas PúblicasNo5:31-51, junho de 1991. Disponível em http://xa.yimg.com/kq/ groups/25228238/1954867300/name/O-conceito-de-Descentralizacao-usos-e-abusos.pdf. Acesso em: 20 mar 2013.

TRAVASSOS, C.; OLIVEIRA, E.X.G.; VIACAVA, F. Desigualdades geográficas e sociais no acesso aos serviços de saúde no Brasil: 1998 e 2003. Ciência \& Saúde Coletiva, Rio de Janeiro, v. 11, n. 4, p. 975-986, 2006.

VIANA, A. L. D.\& LIMA, L. D. [Orgs.] Regionalização e Relações Federativas na Política de Saúde no Brasil. Rio de Janeiro: Contra Capa; 2011. 216 p.

VIANA, A. L. D. ET AL. Novas Perspectivas para a Regionalização da Saúde. São Paulo em Perspectiva; 22(1): 92-106, 2008. 
VIANNA, S. M. NUNES, A. SANTOS, J. R. S. S. e BARATA, R. B. Medindo as desigualdades em saúde no Brasil: uma proposta de monitoramento. Brasília: OPAS/IPEA, 2001.

WAGNER, G. Efeitos Paradoxais da Descentralização no Sistema Único de Saúde no Brasil. In Democracia, descentralização e desenvolvimento: Brasil \& Espanha, org Sonia Fleury. Rio de Janeiro:FGV Editora. Pag 417, 2006.

WERNECK VIANNA, M L T. O culpado é o mordomo? Constrangimentos outros (que não os do modelo econômico) à seguridade social. In LOBATO, L. de V. C. e FLEURY, S. (Org.). Seguridade Social, Cidadania e Saúde. Rio de Janeiro: Cebes, 2009, pag 73. Disponível em http://www.cebes. org.br/media/File/Livro_Seguridade.pdf. Acesso em 17/022012. Acessoem: 16 mar 2013.

WORLD HEALTH ORGANIZATION (WHO). Constitution of the World Health Organization. Disponível em http://apps.who.int/gb/bd/PDF/bd47/EN/constitution-en.pdf. Acesso em: 16 fev 2013.

WORLD HEALTH ORGANIZATION (WHO). Diminuindo diferenças: a prática das políticas sobre determinantes sociais da saúde. Genebra: OMS, 2011. Disponível em: www.who.int/ sdhconference/discussion_paper/Discussion_Paper_PT.pdf. Acesso em: 07 jan. 2013. 